\title{
A metodologia da problematização com o Arco de Maguerez uma perspectiva teórica e epistemológica
}

\section{Neusi Aparecida Navas Berbel \\ Prof $^{a}$ Assistente na Universidade Estadual de Londrina Sílvio Ancizar Sánchez Gamboa \\ Prof. Titular na Universidade Estadual de Campinas}

\section{Resumo}

Este texto apresenta uma síntese de um estudo realizado com base na literatura e análise de conteúdo, de caráter epistemológico, que focalizou a Metodologia da Problematização com o Arco de Maguerez - como caminho de ensino e de pesquisa -, com vistas a compreender as teorias da educação e/ou concepções de conhecimento que a fundamentam. São descritas três versões de explicação e de uso do Arco de Maguerez, cada qual associada a diferentes fontes teóricas e pressupostos epistemológicos. As versões indicam um processo de renovação no contexto das teorias críticas e das epistemologias da práxis. Dessa forma, a Metodologia da Problematização revela maior sustentação teórica e epistemológica e aplicabilidade no campo do ensino e da pesquisa.

Palavras-chave: Metodologia da Problematização; Arco de Maguerez; Teorias pedagógicas; Análise epistemológica.

\section{Resumen}

Este artículo presenta una síntesis de un estudio de carácter epistemológico basado en la literatura y el análisis de contenido, centrándose en la Metodología de la Problematización con el Arco de Maguerez - como camino de enseñanza e investigación-, con vistas a comprender las teorías de la educación y/o concepciones de conocimiento que la fundamentan. Son descritas tres versiones de explicación y de uso del Arco de Maguerez, cada cual asociada a diferentes fuentes teóricas e supuestos epistemológicos. Las versiones muestran un proceso de renovación en el contexto de las teorías críticas y de las epistemologías de la práxis. De esa forma, la Metodología de la Problematización revela mayor sustentación teórica y epistemológica y aplicabilidad en el campo de la enseñanza y de la investigación.

Palabras-clave: Metodología de la Problematización; Arco de Maguerez; Teorías pedagógicas; Análisis epistemológico.

(C) Filosofia e Educação (Online), ISSN 1984-9605

Volume 3, Número 2, Outubro de 2011 - Março de 2012 
A natureza é um livro aberto e o homem pode lê-lo, com a condição, no entanto, de que aprenda a linguagem em que está escrito.

Karel Kosik

\section{Introdução}

Metodologia da Problematização com o Arco de Maguerez
(M.P.) - tem sido alvo de prática e de estudo desde 1992, na
Universidade Estadual de Londrina - UEL, e tem sido estimulada e divulgada também em outras IES do país. Paralelamente à adesão intelectual e afetiva em relação à Metodologia, havia também uma grande inquietação em saber mais sobre as origens do Arco e seus fundamentos teóricos, já que seu anúncio no livro de Bordenave e Pereira (1982), desde 1977, não atendia suficientemente a essas inquietações. Realizamos algumas incursões em autores que percebíamos associados de algum modo às características do Arco de Maguerez, tais como os escritos de Paulo Freire, Adolfo Sánchez Vázquez, dentre outros, mas, de modo um tanto tímido e insuficiente.

A necessidade de termos o domínio teórico para garantir maior segurança científica e também para responder à grande demanda dos interessados na aplicação dessa Metodologia no campo do ensino e da pesquisa, foi, por fim, atendida pela disponibilização de um tempo específico de estudo e pelo acompanhamento de um especialista em pesquisa, filosofia e epistemologia, que nos possibilitaram buscar respostas para essa inquietação. Empenhamo-nos, então, em aprofundar o conhecimento a respeito dos fundamentos dessa metodologia. Traduzimos essa necessidade num problema de estudo, orientado pela seguinte questão: Levando em conta as características do Esquema do Arco, de Charles 
Maguerez, o que o fundamenta? Que teorias da educação elou concepções de conhecimento pode melhor explicá-lo?

Quisemos alcançar, com o estudo, o objetivo geral de analisar características do Esquema do Arco de Maguerez utilizado na Metodologia da Problematização, de modo a identificar teorias da educação $e$ pressupostos epistemológicos com os quais elas se relacionam. Nesse sentido, estabelecemos como objetivos específicos: 1- delinear as características básicas do Arco de Maguerez e as explicações iniciais de que dispomos, como ponto de partida para o estudo; 2- identificar, entre as teorias da Educação, as que se apresentavam mais próximas das características da M.P. e em que referências se apoiam; 3- estabelecer as possíveis relações entre tais referências e as características do Esquema do Arco de Maguerez; 4- ponderar sobre pontos de apoio convergentes e divergentes das referências teóricas associadas ao Arco e que tenham, portanto, maior poder explicativo para o mesmo.

Propusemo-nos a utilizar, como método de investigação, os três graus ou momentos de elaboração, conforme Karel Kosik (2002):

1- minuciosa apropriação da matéria, pleno domínio do material, nele incluídos os detalhes históricos aplicáveis, disponíveis.

2- análise de cada forma de desenvolvimento do próprio material.

3- investigação da coerência interna, ou da determinação da unidade das várias formas de desenvolvimento.

Organizamos o texto em duas grandes partes. Na primeira parte, descrevemos as três versões de explicação para o Arco de Maguerez que identificamos: 1- O Arco explicado por Charles Maguerez; 2- O Arco de Maguerez na segunda versão de explicação e uso (por Bordenave e Pereira, 1982); 3- A Metodologia da Problematização com o Arco de Maguerez e o terceiro exercício de explicação (por Berbel, 1995, 1996 entre outros

(C) Filosofia e Educação (Online), ISSN 1984-9605

Volume 3, Número 2, Outubro de 2011 - Março de 2012 
textos). Com isso, desenvolvemos parte do primeiro momento de investigação proposto por Kosik e alcançamos o primeiro objetivo específico do estudo.

$\mathrm{Na}$ segunda parte, apresentamos uma fundamentação epistemológica para o Arco de Maguerez, organizada em duas fases. Na primeira delas, tratamos a Metodologia da Problematização como um caminho metodológico para o ensino. Nesse ponto nos perguntamos: A que pedagogia(s) pode estar associada? Abrimos três tópicos para a análise de cada uma das três versões de explicação descritas na primeira parte, completando-se essa fase com uma síntese provisória do que detectamos de especial entre a proposta inicial e a mais atual. Tratamos, na segunda fase, da M.P. como um caminho de pesquisa, e para tanto, fazemos uma análise a partir do esquema paradigmático de Sánchez Gamboa (2007), buscando passar por quatro níveis: o técnico, o metodológico, o teórico e o epistemológico.

Na segunda parte, portanto, combinamos os momentos dois e três do método investigativo proposto por Kosik (2002) e pensamos ter atingido os três objetivos específicos que nos propusemos, mesmo que não tenhamos esgotado todas as possibilidades de análise. Esta é a síntese da proposta. Vejamos o que foi possível descobrir em cada uma das partes da investigação para chegarmos à resposta ao problema.

\section{As origens primeiras do Arco de Maguerez e suas ressignificações}

Depois de trabalharmos vários anos com a M.P., as origens primeiras do Arco de Maguerez foram desvendadas com o acesso a fontes primárias textos elaborados por esse autor:

1- em 2003 - acessamos parte de um relatório assinado por Maguerez (1970), para a Coordenadoria de Assistência Técnica Integral - 
CATI, da Secretaria da Agricultura do Estado de São Paulo (em que apresenta sua proposta do Arco);

2- em 2009 - conhecemos o livro de Maguerez (1966), em que descreve seis anos de experiência de formação de profissionais adultos analfabetos para o trabalho em minas, na agricultura ou na indústria, em países em desenvolvimento ou recém-ingressos no grupo de países independentes, envolvendo a Europa e países da África.

Esse último material foi surpreendente e decisivo para compor a $1^{\mathrm{a}}$ explicação de uso para o Arco. Nele não encontramos a menção da formulação de problemas no processo com os grupos, seja pelos monitores seja pelos aprendizes. Além disso, as decisões todas eram centradas nos elaboradores da proposta pedagógica de transferência de tecnologia. Relembramos aqui o formato do esquema de progressão pedagógica (Arco) citado por Maguerez (1966, p.65), em que OR = Observação da Realidade; $\mathrm{OM}=$ Observação da Maquete; $\mathrm{DS}=$ Discussão; EM = Execução na Maquete; ER = Execução na Realidade.

\begin{tabular}{|c|c|c|c|}
\hline & Observação & Discussão & Execução \\
\hline Esquema & & $(\overrightarrow{\mathrm{DS}})$ & \\
\hline Maquete & $(\overrightarrow{O M})$ & & ${ }^{\prime} \quad(\overrightarrow{E M})$ \\
\hline Real & $(\overrightarrow{\mathrm{OR}})$ & & $\times(\overrightarrow{E R})$ \\
\hline
\end{tabular}

Figura 1 - Esquema de progressão pedagógica, de Maguerez 
Tal esquema se repetiria no documento de 1970, de cuja análise percebemos indicações de um trabalho muito mais centrado nos executores da proposta que em seus públicos-alvo, e as atividades propostas nos parecerem muito mais informativas da parte dos monitores ou técnicos e reprodutivas da parte dos aprendizes que reflexivas da parte desses últimos, distanciando-se das aplicações que temos buscado realizar e orientar por meio da utilização do Arco, seja no ensino seja na pesquisa e também da segunda versão de uso e explicação, com Juan Díaz Bordenave.

A análise da segunda versão de explicação realizou-se por meio de três fontes impressas:

1- uma assinada por Bordenave e Pereira (1982) - o livro Estratégias de ensino aprendizagem. Encontramos nesse livro o Esquema do Arco que viríamos a utilizar depois, com pequena alteração em seu desenho:

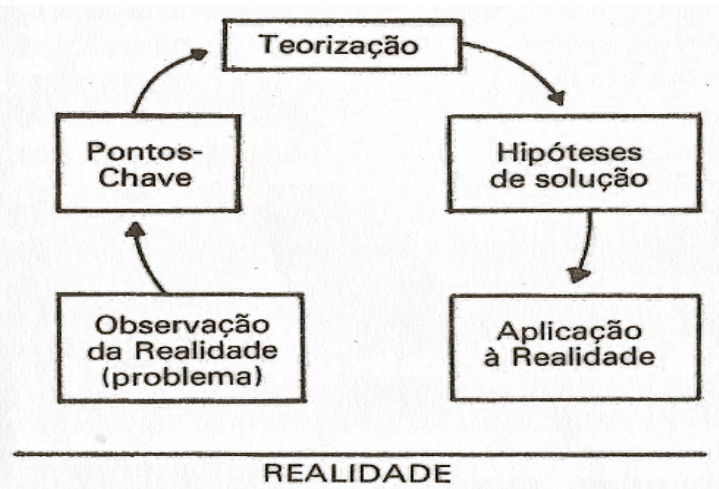

Figura 2- Esquema do Arco de Maguerez, segundo Bordenave e Pereira (1982)

2- em 1989, um pouco depois de acessar o livro, conhecemos a segunda fonte - um texto assinado por Bordenave, em que compara três pedagogias: a da transmissão, a do condicionamento e a da problematização e traz outras explicações para o Arco;

(C) Filosofia e Educação (Online), ISSN 1984-9605

Volume 3, Número 2, Outubro de 2011 - Março de 2012 
3- em 2009, a terceira fonte foi um texto com apontamentos para uma palestra que proferiu como convidado e na qual tratou do Método da Problematização: fundamentos teóricos e aplicações no ensino superior. Tais apontamentos nos foram disponibilizados e nele encontramos um relato de como foi o encontro de Juan Diaz Bordenave com o Arco de Maguerez e seu modo de lidar com ele.

Com a análise do terceiro texto de Bordenave ficou bastante evidente um misto de influências teóricas que marcam seu trabalho em relação ao Arco de Maguerez. Ele mesmo mencionou as ideias de Paulo Freire, algumas ideias de Jean Piaget, o acesso que teve ao que compreendeu como três expressões do construtivismo - a aprendizagem por descoberta, inspirada nas ideias de Jean Piaget; - a concepção sociointeracionista da aprendizagem sustentada nos estudos de Lev Vygotski e desenvolvida por Jerome Bruner; e a aprendizagem significativa de David Ausubel. Por último, por sua afirmação, o próprio autor constatou que a educação problematizadora encontrava fundamentação epistemológica no pensamento dialético.

A terceira versão de explicação para o Arco de Maguerez (BERBEL, 1995, 1996, 1998a, 1998b, entre outros) apoiou-se bastante em Bordenave e Pereira (4ª edição em 1982), ganhando depois nova consistência teórica e epistemológica pela associação explícita do caminho metodológico com o conceito de práxis e suas características, de Adolfo Sánchez Vázquez (1977), e com ideias de Paulo Freire (BERBEL, 1999), apropriadas de alguns de seus livros, com as quais víamos muita afinidade e que conjugamos para ir caracterizando nossos usos e orientações.

O Arco que utilizamos, a partir de Bordenave e Pereira, tem o seguinte desenho: 


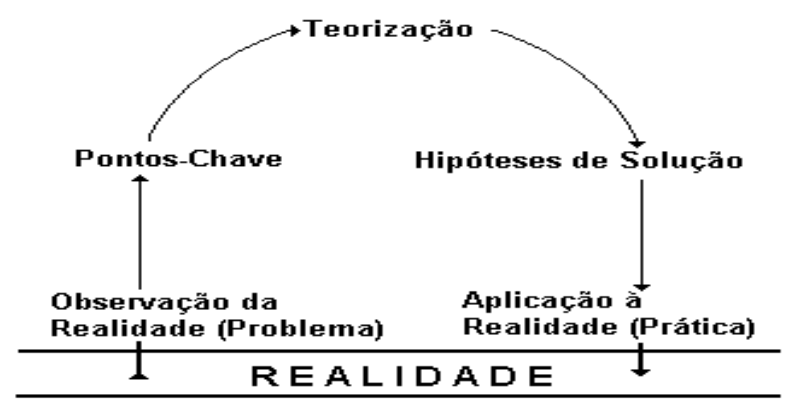

Figura 3 - Arco de Maguerez utilizado por Berbel, a partir de Bordenave e Pereira

A partir do conteúdo descrito na primeira parte do trabalho, pudemos constatar que:

1- cada uma das três versões de uso do Arco de Maguerez tinha uma população-alvo diferente;

2- as três versões apresentavam-se com preocupação pedagógica, de formação, de educação de seres humanos;

3- a problematização ou a elaboração de problemas não estava presente na $1^{\mathrm{a}}$ versão e as decisões eram centradas nos elaboradores da proposta;

4- na segunda versão os problemas eram elaborados pelos professores/ autores do livro, diferente de terceira versão;

5- embora com nuances e palavras diferentes, encontramos, nas duas primeiras versões, indícios de características do método dialético, qual seja, em Maguerez (1970), por seguir os três momentos de tese, hipótese e síntese e, em Bordenave e Pereira (1982, p. 10), por associar os termos síncrese, análise e síntese, sendo que, segundo os 
autores, "a síntese tem continuidade na práxis, isto é, na atividade transformadora da realidade";

6- Maguerez buscava ultrapassar a concepção tradicional de formação, assim como Bordenave e Pereira, que já apontam para a problematização e para a práxis problematizadora;

7- nas três versões, a ideia de partir do concreto, caminhar para o abstrato e retornar ao concreto, sendo que foi ganhando novas denominações e tomando novos contornos nas versões 2 e 3 ;

8- alguns termos do Arco e seus significados no processo foram alterados da $1^{\mathrm{a}}$ para a $2^{\mathrm{a}}$ versão, como observação da maquete e execução da maquete para pontos-chave e hipóteses de solução respectivamente; mantidos os últimos na $3^{\text {a }}$ versão, com alguma alteração na sua operacionalização, mais voltada para a ação do aprendiz;

9- na terceira versão, os alunos/ os pesquisadores são, portanto, posicionados como protagonistas principais de todo o processo, desde a observação da parcela da realidade e definição do problema de estudo até a realização de algum grau de intervenção naquela parcela da realidade, a fim de contribuir para a sua transformação;

10- como consequência da característica anterior, na terceira versão o professor ou orientador assume um papel importante na condução metodológica do processo, não, porém, como fonte central de informação ou de decisão das ações a cada momento.

Portanto, concluimos que a terceira versão (BERBEL) foi-se distanciando da proposta original de Maguerez $(1966,1970)$ e também, de certa forma, da proposta de Bordenave e Pereira (1982), embora sempre reconhecendo sua influência decisiva como fonte inspiradora de nossas 
elaborações. Na sequência do estudo, apresentamos novos elementos da análise que realizamos.

\section{As três versões do Arco e as relações com as teorias/concepções pedagógicas}

Ao considerar a utilização do Arco de Maguerez como um caminho metodológico para o ensino, tivemos a oportunidade de encontrar indícios importantes que nos permitem iniciar a resposta à nossa indagação sobre a fundamentação epistemológica para o Arco de Maguerez. Tomando o texto de Saviani (2008), em que descreve diferentes concepções e/ou modalidades de pedagogia, associamo-las com as três versões de explicação para o Arco e pudemos fazer algumas constatações.

- A primeira versão - de Charlez Maguerez (1966) - pôde ser associada:

1- com a pedagogia produtivista - por características como necessidade de transferência de tecnologia por trabalhadores nacionais/locais de países em desenvolvimento; a não-tecnicidade e a ignorância de fenômenos simples por parte dos trabalhadores; $a$ redundância na sequência pedagógica e a comunicação oferecida visando-se à eficácia da aprendizagem; entre outras características.

2- com a pedagogia corporativa - por características como o estreitamento das relações entre formação e mercado; o educador que, como tal, é ofuscado, e cede lugar ao treinador; por uma educação como convencimento e treinamento para a eficácia dos agentes que atuam no mercado.

3- com a pedagogia construtivista (Piaget) - pela preocupação em conhecer e em descobrir como ativar os esquemas de pensamento dos grupos de adultos; pela disponibilização de variadas ferramentas de

(C) Filosofia e Educação (Online), ISSN 1984-9605

Volume 3, Número 2, Outubro de 2011 - Março de 2012 
raciocínio no sentido de favorecer a promoção profissional; pela preocupação em utilizar material concreto para favorecer a aprendizagem; e com outras, relacionadas com nuances da pedagogia escolanovista.

4- com a pedagogia tradicional - percebida como associada pelo planejamento, tido como estruturação prévia do programa de ensino; pela insistência na importância da sequência pedagógica simbolizada pelo arco; pela previsão de questões a apresentar obrigatoriamente aos alunos; pelas respostas que se espera obter e a explicação a que pode eventualmente o monitor se reportar; pela lista dos termos e das formas de síntese que devem ser destacadas, repetidas, escritas no quadro, lidas e recopiadas; por um exame final muito completo, entre outras razões.

Com base nas análises das pedagogias feitas por Saviani (2008, p. 81), a Pedagogia tradicional, situada no contexto da concepção humanista tradicional, daria prioridade à teoria, subordinando a prática à teoria $\mathrm{e}$ dissolvendo propriamente a prática na teoria, com a preocupação maior nas teorias do ensino e na resposta à pergunta "como ensinar?". As outras três fazem parte das modalidades da Pedagogia nova, que subordinam a teoria à prática. Buscam respostas para a pergunta como aprender, o que, segundo o autor, levou à generalização do lema "aprender a aprender".

Com tais constatações, concluímos que a questão da coerência epistemológica talvez não estivesse na pauta das preocupações de Maguerez, naqueles momentos - anos 1960 e 1970. No entanto, esse fato não é algo tão localizado naquele tempo nem tão isolado como se possa pensar, na área educacional, no Brasil até os dias de hoje.

- A segunda versão - de Bordenave e Pereira - foi assim associada:

(C) Filosofia e Educação (Online), ISSN 1984-9605

Volume 3, Número 2, Outubro de 2011 - Março de 2012 
1- com a pedagogia libertadora - por declarações dos autores que esclarecem porque optaram pela educação libertadora ou problematizadora, contrapondo-a à educação bancária ou convergente. Trata-se de uma das concepções pedagógicas que Saviani (2008) denominou de contra-hegemônicas.

2- com a concepção dialética - pela indicação de que está situada no contexto da concepção humanista moderna de educação, representada pelos renovadores, no confronto com a concepção humanista tradicional; pela sequência de síncrese, análise e síntese; pelo uso do termo práxis e da expressão atividade transformadora da realidade; pela afirmação de Bordenave (1998) de que a educação problematizadora encontra fundamentação epistemológica no pensamento dialético, em seus princípios centrais; pela afirmação de Bordenave e Pereira (1982), de que "a síntese tem continuidade na práxis, isto é, na atividade transformadora da realidade"; entre outras razões.

3- com a pedagogia construtivista (com base em Piaget) - pela declaração de Bordenave (1998) de que teria feito associações do Arco de Maguerez com uma epistemologia identificada com o construtivismo sequencial (estágios de desenvolvimento, reflexo, segundo Saviani, de um kantismo evolutivo em Jean Piaget) em que sujeito e meio interagem transformando-se reciprocamente; pela afirmação do autor de que "a interação com o meio produziria no sujeito o desenvolvimento de sua estrutura mental e dos esquemas de assimilação que constituem sua inteligência"; entre outras razões.

Também na segunda versão, com Bordenave e Pereira (1982), ou em texto de autoria individual de Bordenave (1998), nos deparamos com uma alternativa inspirada em múltiplas fontes, até mesmo no âmbito do 
construtivismo, tendo, porém, como ponto agregador, o fato de estarem voltadas para uma pedagogia propiciadora de renovação da educação e da escola, numa sociedade em mudança, ideias, também presentes ou integradas ao pensamento pedagógico da Escola Nova.

Tais pedagogias, percebidas na segunda versão, situadas no grupo de pedagogias novas ou renovadas, conforme classificação de Saviani (2008), vão ocupando o espaço, antes marcado pelas características da pedagogia tradicional, na primeira versão de Maguerez. No entanto, segundo esse mesmo autor, devemos prestar atenção ao fato de que o movimento escolanovista se inspira fortemente no pragmatismo, e o Movimento Paulo Freire, que também marcou Bordenave e Pereira, busca inspiração no personalismo cristão e na fenomenologia existencial. Eis um ponto importantíssimo de pauta para novas análises, para as quais contamos com os mesmos textos, mas não com descrições da experiência realizada.

- A terceira versão de explicação - de Berbel - pode ser associada com:

1- a pedagogia construtivista - por afirmações nossas e também de Bordenave ao referir-se ao nosso trabalho - no contexto e entre outros aspectos do movimento da Escola Nova, portanto associado com a Pedagogia da Escola Nova; pela nossa afirmação de tratar-se de um caminho metodológico que conduz à construção do conhecimento pelo aluno ou pelo pesquisador; pelo estímulo à ação do aluno durante todo o processo, incluindo-se uma ação de retorno à parcela da realidade tomada como foco do estudo; pela nossa valorização do "aprender a aprender" (como uma característica do desenvolvimento do aluno e não pelas ideias neo-escolanovistas); entre outras razões.

2- a concepção dialética, a partir da qual se extraiu a noção de práxis, defendida por nós como impregnada no Arco de Maguerez, justificada

(C) Filosofia e Educação (Online), ISSN 1984-9605

Volume 3, Número 2, Outubro de 2011 - Março de 2012 
a partir de características da práxis apresentadas por Adolfo Sánchez Vázquez (1977).

3- a pedagogia libertadora, de Paulo Freire, com a qual associamos explicitamente várias das características da M. P., utilizando para isso passagens dos escritos desse educador.

4- a Pedagogia das perguntas e das respostas, defendida por Sánchez Gamboa e Chaves (2008), na perspectiva crítico-dialética. Tal pedagogia inicia-se "com a problematização e com o olhar crítico sobre a realidade, onde a suspeita, a dúvida, a curiosidade, a indagação, a questão e a pergunta se tornam pontos de partida do conhecimento da realidade" (p. 154), o que afirmamos também para a terceira versão de uso da M.P., entre outras características.

Ao analisarmos a M. P. como um caminho de ensino, tendo como referência principal o estudo das pedagogias por Saviani (2008), concluímos por não poder responder ao nosso problema de estudo com a indicação de uma única teoria da educação como influenciadora do nosso entendimento e da sua utilização no contexto da formação de professores. Percebemos que a primeira versão, marcada pela pedagogia tradicional, foi cedendo espaço para o fortalecimento de características de uma educação ou pedagogia renovada que, por sua vez, foi mesclando-se com traços de outras visões de mundo e de educação, conforme foram sendo divulgadas e incorporadas por educadores, como a versão libertadora e a dialética, na segunda e terceira versões explicativas. Podemos afirmar que ocorreram flutuações entre teorias humanistas modernas da educação - contrapostas à concepção humanista tradicional -, teorias críticas, representadas pela pedagogia fenomenológica, e pedagogias críticas dialéticas, representadas principalmente pela forte ligação percebida e defendida como perspectiva da práxis.

(C) Filosofia e Educação (Online), ISSN 1984-9605 
4- A análise da Metodologia da Problematização e do Arco, sob o esquema paradigmático de Sánchez Gamboa

Ao considerarmos a utilização do Arco de Maguerez como um caminho metodológico para a pesquisa, apoiamo-nos em Sánchez Gamboa (2007), ou seu "esquema paradigmático", para análise de pesquisas em educação. Cumpre-nos explicar que, nesse esquema, ele adota uma classificação das vertentes epistemológicas encontradas em três grandes grupos: as empírico-analíticas, as fenomenológico-hermenêuticas e as crítico-dialéticas. Além disso, ele busca estabelecer uma relação dialética entre a construção da pergunta e a construção da resposta de investigações, propondo quatro níveis para a construção da resposta: nível técnico, nível metodológico, nível teórico e nível epistemológico. A estes acrescenta a identificação de pressupostos gnosiológicos e ontológicos.

Retomamos inicialmente, a caracterização da M.P., tal como a entendemos e procuramos desenvolver. $\mathrm{Na}$ sequência, tomando como referência os processos que o autor define para o nível técnico e o metodológico, tais como os de coleta, registro, organização, sistematização e tratamento dos dados e informações em relação ao primeiro (técnico) e os passos, procedimentos e maneiras de abordar e tratar o objeto investigado, além das formas de aproximação ao objeto (delimitação do todo e sua relação com as partes) e consideração ou não dos contextos (em relação ao nível metodológico).

Percebemos, num primeiro momento, uma aproximação maior da $\mathrm{M}$. P. com duas das vertentes que ele propõe, a fenomenológico-hermenêutica e a crítico-dialética. Ou seja, o que realizamos se distancia da abordagem empírico-analítica, que prevê a utilização de técnicas de registro e tratamento de informações marcadamente quantitativas, instrumentos de coleta de dados estruturados ou padronizados, tratamento estatístico 
sofisticado etc. No entanto, reconhecemos a necessidade de aprofundamento dessa análise.

Tendo como referência as características do nível teórico do esquema paradigmático de Sánchez Gamboa (2007), nossa constatação foi semelhante a dele, relativa aos níveis anteriores, pois pelas características do Arco e de seu desenvolvimento, entre outros aspectos, ele se afasta da abordagem empírico-analítica, já que inclui a crítica, o debate, a polêmica, não se amparando na possibilidade de neutralidade científica, na objetividade do próprio método, ou ainda, na imparcialidade do pesquisador. Pelo contrário, baseia-se numa abordagem preponderantemente qualitativa de pesquisa, tem o pesquisador como um de seus principais instrumentos de investigação, conforme apontado por Bogdan e Bicklen (1994) e propõe a busca de algo relevante para estudar na perspectiva da práxis humana, ou seja, na perspectiva da transformação consciente, informada e intencional da realidade (SÁNCHEZ VÁZQUEZ, 1977; KOSIK, 2002) em algum grau, o que aproxima a M.P. das abordagens críticas.

O quarto nível do esquema paradigmático de Sánchez Gamboa (2007, p. 72) - o nível epistemológico - é caracterizado como o âmbito da “concepção de causalidade, de validação da prova científica e de ciência (critérios de cientificidade)". As perguntas principais seriam: São o processo e os procedimentos utilizados nas pesquisas científicos e verdadeiros? Conduzem ao conhecimento da realidade? Responder a estas questões em relação à M.P. foi e continua sendo o nosso maior desafio.

Se nos níveis anteriores distanciamos as pesquisas com a M.P. das abordagens empírico-analíticas, parece-nos que no nível epistemológico haveria alguma proximidade entre elas e essa abordagem, no desenvolvimento da segunda etapa do Arco, quando o estudante reflete sobre o problema para compreendê-lo melhor, perguntando-se sobre seus 
possíveis fatores e determinantes maiores. Nesse momento, o estudante estabelece algumas hipóteses explicativas iniciais para o problema, antes de definir os pontos a estudar com profundidade na terceira etapa. No entanto, é apenas uma reflexão inicial e não a realização da investigação como um todo, conferindo-se "prioridade à relação causal nas suas formas mais clássicas”, como caracteriza Sánchez Gamboa (2007, p. 87).

Para aprofundar a análise em relação ao nível epistemológico, elegemos um dos focos, percebido como presente em todas as três versões de explicação para o Arco de Maguerez - a relação entre teoria e prática (T e P), e destacado a partir da terceira versão de explicação para o Arco (BERBEL), como a associação com o conceito de práxis, que declaramos, com convicção, existir, e nos perguntamos: - Se a M.P. possui o potencial metodológico de levar ao exercício da práxis, a que práxis nos estamos referindo?

Tomamos a explicação geral de Saviani (2008, p. 126) segundo a qual "teoria e prática são aspectos distintos e fundamentais da experiência humana". Existem especificidades que os diferenciam. No entanto, são "aspectos inseparáveis, definindo-se e caracterizando-se sempre um em relação ao outro". O autor segue explicando que a prática é a razão de ser da teoria, de modo que a teoria só se constituiu e se desenvolveu a partir de uma prática, que lhe fornece, ao mesmo tempo, o fundamento, a finalidade $\mathrm{e}$ o critério de verdade. Pensamos que essa lógica está inserida na sequência de etapas do Arco de Maguerez pelo uso que dele fazemos.

Sánchez Gamboa (1995, p.32) afirma que T e P apresentam uma relação dinâmica e contraditória: "a teoria transforma-se na negação da prática porque a tenciona; a prática coloca em xeque a teoria, porque, em vez de se ajustar a ela, transforma-se em seu contrário". É assim que a relação entre $\mathrm{T}$ e $\mathrm{P}$ pode ser compreendida como uma relação dialética. $\mathrm{E}$ por ser dialética, não procura o equilíbrio, o ajuste, a acomodação de uma à 
outra, mas a sua contradição, ou seja, há uma tensão permanente entre elas, que se sintetiza na práxis. É por esse modo que o conhecimento avança.

Sánchez Vázquez (1977, p. 215) explica que a teoria depende da prática, "na medida que a prática é fundamento da teoria, já que determina o horizonte de desenvolvimento e progresso do conhecimento". Para o autor, o conhecimento científico-natural progride no processo de transformação do mundo natural. Isso ocorre em virtude de que "a relação prática que o homem estabelece com ele, mediante a produção material, coloca-lhe exigências que contribuem para ampliar tanto o horizonte dos problemas como o das soluções. É do mesmo autor a afirmação:

A dependência da teoria em relação à prática, e a existência desta como últimos fundamentos e finalidade da teoria, evidenciam que a prática concebida como uma práxis humana total - tem primazia sobre a teoria; mas esse seu primado, longe de implicar numa contraposição absoluta à teoria, pressupõe uma íntima vinculação com ela (SÁNCHEZ VÁZQUEZ, 1977, p.234).

Entendemos que podemos exercitar uma práxis por meio da Metodologia da Problematização com o Arco de Maguerez. Nesse processo, $\mathrm{T}$ e $\mathrm{P}$ se articulam desde o início, visto que tanto a teoria quanto a prática considerada e realizada se apresentam em níveis variados de elaboração, dependendo das condições concretas de que dispomos em cada grupo e com cada grupo ou pessoa e ambiente, mas sempre com a intenção clara de seu desenvolvimento cada vez mais consciente e elaborado.

Mas que tipo de práxis é possível realizar por esse caminho? Recorremos a Kosik (2002) e a Sánchez Vázquez (2007), que caracterizam o sentido de práxis que adotam, e distinguem alguns tipos e ou níveis da práxis. Encontramos em Kosik a distinção entre a práxis cotidiana utilitária e fragmentária, ou fetichizada, própria de uma consciência ingênua, e uma práxis crítica e revolucionária da humanidade, fruto de uma consciência 
crítica, que passa pela necessária destruição da pseudoconcreticidade como método dialético crítico.

Analisando características do desenvolvimento da M.P. com o Arco de Maguerez e as ideias de Kosik a respeito da práxis, constatamos que pela M.P. a busca é por ultrapassar a práxis cotidiana e exercitar, em algum grau, uma práxis revolucionária, no âmbito da educação, mesmo que em proporções singelas.

Em Sánchez Vázquez (2007), encontramos dois níveis principais de práxis: a práxis criadora que se contrapõe à práxis reiterativa ou imitativa, e a práxis reflexiva que se contrapõe à práxis espontânea. $\mathrm{O}$ autor alerta, com relação a muitos outros aspectos, para a possibilidade de vínculos mútuos entre um nível e outro, o que determina tipos peculiares de relações sociais.

A terceira versão (BERBEL) ultrapassa uma práxis simplesmente reiterativa ou imitativa, por atuar com, assim como levar os alunos a conquistar graus cada vez mais elevados de uma práxis criadora, justamente pela reflexão estimulada em cada etapa da M. P., e pelas características que lhe são próprias ou lhe são atribuídas, como as de: tomar um recorte de realidade como ponto de partida e de chegada do estudo; reconhecer a constante relação entre $\mathrm{T}$ e $\mathrm{P}$ ao longo do percurso em cada estudo; considerar a realidade concreta para aprender com ela e para nela intervir, em busca de soluções para seus problemas; conscientizar-se da complexidade dos fenômenos sociais; entre outras.

Reconhecemos o grande desafio que nos impomos, quando propomos esse caminho aos nossos alunos ou estimulamos sua aplicação por outros professores formadores no ensino superior ou mesmo em outros níveis de ensino, pela grande determinação exigida e pela clareza da opção necessária nesse caminho e por ele se apresentar como um caminho que não se coaduna com tendências mais modernas de educação, de mais fácil adesão.

(C) Filosofia e Educação (Online), ISSN 1984-9605

Volume 3, Número 2, Outubro de 2011 - Março de 2012 


\section{5 - Alguns aspectos conclusivos}

Como algumas considerações finais, podemos afirmar que, na terceira versão de explicação e uso da M. P., nos foi possível identificar indícios de uma maior dialeticidade na relação entre $\mathrm{T}$ e $\mathrm{P}$, pelas características esboçadas que realçam a orientação explícita na busca por alcançar o sentido da práxis numa perspectiva crítica transformadora. Portanto, a resposta possível ao nosso problema de estudo, neste momento, é a de que vários aspectos apontam para uma ênfase maior nos pressupostos da dialética materialista fundamentando teoricamente essa metodologia.

Ao mesmo tempo que apostamos no exercício da práxis pela experiência de percorrer todas as etapas do Arco de Maguerez, reconhecemos que ainda há a necessidade de fortalecimento da fundamentação teórica a respeito da própria relação entre $\mathrm{T}$ e $\mathrm{P}$ por todos aqueles que experimentam a M. P. em seus trabalhos. Isso para assumirmos com maior clareza o sentido de práxis criadora, conduzindo os estudos e as práticas deles decorrentes. Mesmo assim, reafirmamos que há uma boa dose de prática e teoria imbricadas uma à outra, e associadas ao objeto e ao desenvolvimento do estudo de cada participante, embora a concepção filosófico-epistemológica se apresente timidamente nos relatórios dos trabalhos em geral, sendo essa uma das razões de ampliarmos nosso conhecimento para podermos influenciar os nossos orientandos mais decisivamente nesse aspecto.

Partir de uma prática social existente, passar por um amplo processo de reflexão sobre um dos problemas ali detectados e depois retornar para a parcela da realidade da qual o problema foi extraído, com alguma prática, desta vez mais informada, de modo consciente e intencionalmente transformadora, é realmente uma proposta de trabalho ativo, que envolve uma boa dose de reflexão - sendo por isso também crítico - e se complementa com algum grau de transformação da realidade. 
Não se pode admitir que esse caminho seja apenas ativo, porque há um sentido crítico e criativo orientador da atividade intensa envolvida. Podemos indagar: T e $\mathrm{P}$, nesse caso, são apenas complemento um do outro? Ou são opostos que se incluem, como afirmou Saviani (2008, p.127)? Parece-nos que essa discussão seja pertinente em cada ocasião de uso da Metodologia da Problematização com o Arco de Maguerez. Teoria e prática não se constituem como a mesma coisa. São elementos opostos, que podem se apresentar dinâmica e contraditoriamente (SÁNCHES GAMBOA, 1995) no processo de construção do conhecimento pelos participantes e na construção de sua profissionalização e da sua cidadania.

A cada conflito percebido e superado nessa relação entre $\mathrm{T}$ e $\mathrm{P}$, mais positiva se torna a provocação do ser humano que o toma como objeto de estudo. A ideia de que a teoria se transforma na negação da prática, porque tenciona a esta e esta coloca em xeque a teoria (SÁNCHES GAMBOA, 1995), poderá fortalecer o sentido dialético do trabalho com a M. P. no tratamento de questões da educação ao ser profundamente compreendida.

Se no discurso, a terceira versão (BERBEL) muito se aproxima da relação dialética entre $\mathrm{T}$ e $\mathrm{P}$, na prática pode ser ainda mais profundamente analisada para termos mais comprometido com o sentido do trabalho aquele que o desenvolve, e, por isso, conquistar graus cada vez maiores de autonomia em relação a quem conduz o processo. Nesse sentido, a práxis criadora ou criativa pode evoluir para uma práxis revolucionária, ao apoiarse em instrumentos e técnicas valorizados pela Escola Ativa, fazendo avançar parte dos estudantes para uma postura dialética e crítica, que corresponda a essa concepção. Também nesse sentido, a consciência ingênua ou consciência comum pode ser ultrapassada facultando ao indivíduo alcançar, claro, não sem muito empenho e disposição, uma consciência filosófica da práxis, que não é privilégio dos filósofos. 
Se os participantes de um processo com a Metodologia da Problematização compreendem que toda práxis é atividade, mas nem toda atividade é práxis, conforme se lê em LEONTIEV (1983), todo o processo pode ser intencionalmente impregnado de atuação com o sentido de uma práxis consciente, criativa e crítica. As etapas da Metodologia da Problematização possuem um potencial estimulador do estudante nessa direção.

Parece-nos, portanto, que é possível passar pelas atividades do Arco inspirando-nos na Escola Nova ou na perspectiva dialética. Nesse caso, a definição deve ser resultado de uma escolha dos envolvidos, mediada pelas convicções destes e pelas finalidades a que se propuserem. A superficialidade do entendimento da proposta pode gerar implicações que caracterizem tanto um praticismo, quanto um pragmatismo ou uma postura de construção do conhecimento e de ação consequente no meio, esta última própria de uma práxis crítica e criadora.

Se não há dúvida, para nós, quanto à relevância da questão orientadora de nosso estudo, certamente podemos afirmar que não temos até agora, apesar do esforço empreendido, uma resposta suficiente. Temos, no entanto, um bom início de exame da questão. O que encontramos analisando os discursos, principalmente em relação à terceira versão de explicação (BERBEL) para a utilização do Arco, poderá vir a ser aprofundado, pela analise de pesquisas realizadas com esse caminho e, melhor ainda, pelo conhecimento de seus resultados, principalmente pela informação de quem vivenciou as formas de aplicação realizadas e sentiu os seus efeitos. Além disso, a análise teórica de outros ângulos e com maior profundidade poderá ajudar a fortalecer ou não algumas das suspeitas de associações consideradas mais evidentes e ou descartar outras menos adequadamente associadas. 
O que pensávamos, portanto, que seria o final de um ciclo de estudos, apenas nos colocou diante de um amplo processo de investigação pleno de possibilidades. Para exemplificar nossa consciência clara dessa afirmação, acrescentamos o necessário aprofundamento de análise das vertentes teóricas que apoiam a proposta da pedagogia libertadora de Paulo Freire, outro foco que se destaca em nossas elaborações anteriores, que aqui ficou apenas anunciado como um dos tratamentos iniciais da M.P., permanecendo o desafio para a continuidade da investigação.

\section{Referências}

BERBEL, N. A. N. A metodologia da problematização e os ensinamentos de Paulo Freire: uma relação mais que perfeita. In: BERBEL, N. A. N. (Org.). Metodologia da problematização: fundamentos e aplicações. Londrina: EDUEL/COMPEd - INEP, 1999. p. 1-28.

BERBEL, N. A. N.(Org.). Metodologia da Problematização: fundamentos e aplicações. Londrina: Ed. UEL/ COMPEd - INEP, 1999.

BERBEL, N. A. N. A Metodologia da Problematização no ensino superior e sua contribuição para o plano da práxis. Semina, Ci. Soc./Hum., Londrina: v. 17, p. 7-17, nov./1996. Edição Especial.

BERBEL, N. A. N. Metodologia da Problematização. Experiências com questões de ensino superior. Londrina: EDUEL, 1998a.

BERBEL, N. A. N. Metodologia da Problematiz̧ação. Experiências com questões de ensino superior, ensino médio e clínica. Londrina: EDUEL, 1998b.

BERBEL, N. A. N. Metodologia da Problematização: uma alternativa metodológica apropriada ao Ensino Superior. Semina, Ci. Soc./Hum., Londrina, v. 16, n. 2, p. 9-19, out. 1995.

BOGDAN, R.; BIKLEN, S. Investigação qualitativa em educação: uma introdução à teoria e aos métodos. Porto: Porto Editora, 1994.

BORDENAVE, J.D.; PEREIRA, A. M. Estratégias de ensino aprendizagem. 4. ed. Petrópolis: Vozes, 1982. 
BORDENAVE, J. E. D. Alguns fatores pedagógicos. In: BRASIL. Ministério da Saúde. Secretaria Geral. Capacitação pedagógica para instrutor/supervisor. Área da saúde. Brasília, 1989. p. 19-26. Texto traduzido e adaptado por Maria Thereza Grandi, do artigo La transferência de tecnologia apropriada ao pequeno agricultor.

BORDENAVE, J. E. D. Método da Problematização: fundamentos teóricos e aplicações no ensino superior. Londrina, 1998. Anotações de palestra proferida na Universidade Estadual de Londrina.

KOSIK, K. A dialética do Concreto. 7. ed. Rio de Janeiro: Paz e Terra, 2002.

LEONTIEV, Alexei N. Actividad, consciencia e personalidad. Havana: Editorial Pueblo y Educación, 1983.

MAGUEREZ, C. Elementos para uma pedagogia de massa na assistência técnica agrícola. In. MAGUEREZ, C. Análise do sistema paulista de assistência à agricultura. Campinas, 1970. Extraído do Relatório apresentado à Coordenadoria de Assistência Técnica Integral - CATI.

MAGUEREZ, C. La promotion technique du travailleur analphabete. Paris: Editions Eyrolles, 1966.

SÁNCHEZ GAMBOA, S. Pesquisa em educação: métodos e epistemologias. Chapecó: Argos, 2007.

SÁNCHEZ GAMBOA, S. Teoria e prática. Uma relação dinâmica e contraditória. Motri-Vivência, Florianópolis, v. 6, n. 8, p. 31-45, dez. 1995.

SÁNCHEZ GAMBOA, S.; CHAVES, M. A relação universidade e sociedade: a "problematização" nos projetos articulados de ensino, pesquisa e extensão. Educação Temática Digital. Campinas, v.10, n. 1, p.144-167, dez. 2008.

SÁNCHEZ VÁZQUEZ, A. Filosofia da Práxis. Tradução de Maria Encarnación Moya Buenos Aires: Consejo Latinoamericano de Ciências Sociales-CLACSO, 2007.

SÁNCHEZ VÁZQUEZ, A. Filosofia da Práxis. 4. ed. Rio de Janeiro: Paz e Terra, 1977.

SAVIANI, D. A pedagogia no Brasil. História e teoria. Campinas: Autores Associados, 2008. 